\title{
Centro acadêmico: o papel da entidade estudantil na formação acadêmica, profissional e social do discente
}

Academic center: the role of the student entity in the academic, professional and social training of the discent

\author{
Alan da Costa Moura ${ }^{(i D}$, Romana Fátima Rodrigues de Sousa ${ }^{2}($ D \\ ${ }^{1}$ Universidade Federal do Ceará (UFC), Brasil, graduando em Administração (UFC), e-mail: alan.mourah@gmail.com \\ ${ }^{1}$ Universidade Federal do Ceará (UFC), Brasil, graduada em Secretariado Executivo (UFC), e-mail: \\ romanafrsousa@gmail.com
}

\section{RESUMO}

Este estudo investigou como a participação do discente do curso de Secretariado Executivo da Universidade Federal do Ceará no Centro Acadêmico pode contribuir com o seu desenvolvimento acadêmico, profissional e social. A pesquisa se justifica pela necessidade de demonstrar a influência da participação na entidade na formação do estudante. A abordagem teórica considerou autores como Silva et al. (2017), Fleury e Fleury (2001), Souza (2004), dentre outros. Metodologicamente, realizou-se um estudo de caso qualitativo e descritivo, por meio de entrevista indireta a 17 participantes do Centro Acadêmico de Secretariado Executivo. Os principais resultados apontam que a entidade agrega valor por aumentar o engajamento na universidade; garantir o contato com competências, como comunicação, controle emocional, liderança, planejamento e programação de projetos; e propiciar o convívio com causas sociais. Destarte, a entidade é capaz de contribuir para a formação universitária como um todo.

Palavras-chave: Centro Acadêmico. Desenvolvimento Estudantil. Secretariado Executivo.

\begin{abstract}
This paper investigated how the involvement of the student of the Executive Secretariat course at the Federal University of Ceará in the academic center can contribute to their academic, professional, and social development. The research is justified by the need to demonstrate the influence of participation in the entity in the education of the undergraduate. The theoretical approach considered authors such as Silva et al. (2017), Fleury and Fleury (2001), Souza (2004), and others. Methodologically, a qualitative and descriptive case study was conducted, through an indirect interview with 17 participants from the Academic Center of Executive Secretariat. The main results point out that the entity adds value by increasing engagement at the university; guaranteeing contact with competencies, like communication, emotional control, leadership, planning and project scheduling; and by promoting coexistence with social causes. Thus, the entity can contribute to university education as a whole.
\end{abstract}

Keywords: Academic Center. Student Development. Executive Secretariat. 


\section{INTRODUÇÃO}

O desenvolvimento da formação do indivíduo não está relacionado apenas à presença deste em sala de aula nos seus mais diferentes níveis de ensino. O indivíduo, desde o momento mais inicial da vida, vivência experiências que também serão responsáveis por sua formação, seja no âmbito familiar, escolar ou no ciclo de amizades. Em nível educacional, o ensino superior tem dentro de suas finalidades formar o indivíduo para a sua melhor atuação em sociedade, não só na esfera profissional, mas na amplitude do ser cidadão e da própria busca constante por conhecimento.

Dentre as maneiras de vivenciar essas experiências dentro da Instituições de Ensino Superior (IES), o Centro Acadêmico (CA) apresenta-se como uma forma do universitário não se prender apenas aos momentos em sala de aula. Assim, tais entidades auxiliariam no desenvolvimento daqueles que a compõem, trazendo novos aprendizados que podem ajudá-los no mercado de trabalho. Em relação a esse ambiente mercadológico, Kilimnik, Sant'anna e Luz (2004), afirmam que este cenário espera que seus profissionais busquem o aprendizado contínuo.

Dessa maneira, é interessante descobrir como os CAs se apresentam como uma ferramenta das IES na formação de seus alunos. Para isso, este trabalho tem como questão norteadora: de que maneira a participação em um Centro Acadêmico colabora com a formação acadêmica, profissional e social do discente? O objetivo geral, portanto, é conhecer como a participação do discente do curso de Secretariado Executivo da Universidade Federal do Ceará (UFC) no Centro Acadêmico pode contribuir com o seu desenvolvimento acadêmico, profissional e social. Foram definidos como objetivos específicos: identificar os motivos relacionados à escolha do discente em participar do Centro Acadêmico de Secretariado Executivo; identificar as competências que estão relacionadas com as atividades desenvolvidas pelos discentes de Secretariado Executivo no Centro Acadêmico; e apontar os benefícios da participação em um Centro Acadêmico para a formação acadêmica, profissional e social do discente.

O desenvolvimento desse trabalho se justifica pela necessidade de demonstrar como a trajetória vivida em um CA pode contribuir para a formação dos discentes nos âmbitos acadêmico, profissional e social. Esta atuação que se configura como algo complementar aos momentos em sala de aula, é um aspecto considerado importante pelas Diretrizes Curriculares

Revista Expectativa, Toledo/PR, v.20, n. 3, p. 22-45, jul./set., 2021. 
Nacionais (DCN) do curso de graduação em Secretariado Executivo, pois as atividades complementares são de suma importância para o enriquecimento e a implementação do perfil do discente (BRASIL, 2005). O estudo ainda se justifica por verificar o quão abrangente pode ser a formação proposta pelas IES, incluindo atividades obrigatórias e complementares, tendo em vista que, segundo a lei n ${ }^{\circ}$ 9.394/96, a educação nessas instituições demonstra sua relevância quando é capaz de transformar discentes em sujeitos aptos ao convívio em sociedade, exercendo seus papéis de cidadãos, profissionais e acadêmicos (BRASIL, 1996).

Quanto à estrutura, este trabalho está organizado em quatro seções, além desta introdução. O referencial teórico traz uma explanação acerca dos CAs, além de discorrer sobre competências. A terceira seção apresenta a metodologia adotada na pesquisa, sendo seguida da quarta seção que expõe os resultados e discussões. Por fim, a quinta seção aborda sobre as considerações finais, seguida das referências que contribuíram no desenvolvimento desta pesquisa.

\section{REFERENCIAL TEÓRICO}

\subsection{CENTROS ACADÊMICOS: SURGIMENTO, CARACTERÍSTICAS}

As IES do âmbito público, exercendo o seu papel formador, objetivam desenvolver o aluno para o cumprimento do seu papel no meio social, considerando aspectos pessoais, sociais e profissionais. Os espaços propícios para o alcance do desenvolvimento universitário podem estar relacionados às experiências diretas, como na sala de aula, e às indiretas, como no CA, de maneira que a sejam oportunizadas vivências capazes de contribuir de forma valorosa para diferentes formações.

Considerando que cada nível de ensino possui particularidades e exigências legais, a Lei de Diretrizes e Bases da Educação (LDB), lei n 9.394/96, abrange uma formação estudantil em várias vertentes. Percebe-se isso quando é pontuada a existência dos processos formativos relacionados à convivência humana, ao trabalho, às instituições de ensino e pesquisa, aos movimentos sociais e às organizações da sociedade. Dessa forma, nota-se que as instituições de ensino precisam oportunizar aos estudantes, formas de ensino com direcionamento a essas vertentes que a lei dispõe (BRASIL, 1996).

Revista Expectativa, Toledo/PR, v.20, n. 3, p. 22-45, jul./set., 2021. 
Uma das maneiras de desenvolver essas formações é através de entidades ligadas ao movimento estudantil, que, além do seu caráter representativo, podem favorecer ao aluno participante diferentes experiências e aprendizados. Esse movimento surgiu por volta do final dos anos 50 e início dos anos 60, movidos por inconformações sociais e acadêmicas, onde buscavam-se destaque para os anseios e preocupações estudantis, além do rompimento de estruturas sociais e atualização dos currículos escolares (SOUZA, 1998).

Com o movimento, surgem diversos órgãos que buscam a representação da classe e configuram-se como entidades que possuem um papel ligado diretamente à construção da cidadania. Dentre eles estão os CAs, entidades que defendem os interesses e a representação dos alunos de um curso. Sua existência e atuação nas IES é garantida pela lei $\mathrm{n}^{\circ} 7.395 / 85$, que dispunha sobre os órgãos de representação estudantil em âmbito de ensino superior (BRASIL, 1985).

Nas finalidades de um CA há vertentes acadêmicas, profissionais e sociais. Pode-se notar isso com o estudo de Cavalcante et al. (2014, p. 3), que diz que a entidade lida com “atividades extracurriculares, como debates, discussões, palestras, [...] mobilização e organização de reivindicações e ações políticas dos estudantes; mediação de conflitos [...]; realização de atividades culturais, esportivas e de lazer, dentre outras.”. Já Marin et al. (2011) alegam que as funções do CA estão ligadas ao desenvolvimento do ensino e à formação do discente. Por outro lado, Costa et al. (2017) dizem que a atuação do CA incentiva a participação do discente, representando um elo na relação entre os discentes, coordenação e diretoria.

A participação em um CA pode trazer inúmeros benefícios para os membros que o integram, garantindo o desenvolvimento do indivíduo em diversas áreas. Em relação a essa temática, Silva et al. (2017) apontam como benefícios o aperfeiçoamento em questões relacionadas à organização e à competência profissional, propiciando ao indivíduo interdisciplinaridade, instigando a proatividade, o desenvolvimento de capacidades filantrópicas e a participação em projetos acadêmicos, como palestras e semanas acadêmicas.

Diante desses aspectos, percebe-se que a maneira como os CAs atuam, trazendo vivências que podem contribuir para o desenvolvimento dos discentes e atingir seus objetivos, faz com que estes se configurem como entidades sérias e estruturadas. Lauermann et al. (2012) ainda afirmam que por mais que estas entidades estudantis não se configurem como empresas, as mesmas possuem características de organizações, pois, como afirmado por Meireles (2003,

Revista Expectativa, Toledo/PR, v.20, n. 3, p. 22-45, jul./set., 2021. 
p. 46), organização é "um conjunto articulado de pessoas, métodos e recursos materiais, projetado para um dado fim”, requisitos esses atendidos pelos CAs.

Diferente da obrigatoriedade da participação dos discentes em sala de aula para o cumprimento da carga horária requisitada para a conclusão do curso, o engajamento nas entidades estudantis está relacionado a diferentes razões e motivações. Oliveira (2017) demonstra a importância dessa motivação quando diz que é por meio dela que um sujeito é estimulado a realizar determinada tarefa. Fonseca et al. (2018) afirmam em seu estudo que diversos fatores estão atrelados ao ingresso em um CA, como insatisfação com o atual funcionamento da entidade estudantil, o sentimento de acreditar no potencial de mudança do CA e razões ligadas a experiências ao longo da vida desses discentes.

Ainda considerando a não obrigatoriedade da participação dos discentes em entidades estudantis, pode-se notar que a participação em um CA configura-se como uma atividade extracurricular complementar e, por isso, consegue trazer ao discente o contato com a "prática de estudos e atividades independentes, transversais, opcionais, de interdisciplinaridade, especialmente nas relações com o mundo do trabalho, com as peculiaridades das organizações e com as ações de extensão junto à comunidade.” (BRASIL, 2005, p. 21). Dessa maneira, notase que devido a abrangência das atividades executadas em um CA, aqueles que se propõem a participar desse tipo de entidade podem adquirir e aperfeiçoar aspectos relevantes para a construção do seu perfil profissional.

Dessa forma, paralelo ao ensino em sala de aula, aproveitar as oportunidades oferecidas durante a graduação, como $\mathrm{CA}$, grupos de pesquisa, empresa júnior, estágio, dentre outros, contribui para uma maior amplitude no desenvolvimento do discente. Confirma-se isso com o pensamento de Müller, Oliveira e Cegan (2015, p. 148), quando os autores afirmam que "uma formação abrangente, respeitando as delimitações técnicas, teóricas e sociais, têm maiores probabilidades de formar profissionais preparados para o enfrentamento das dinâmicas complexas dos ambientes empresariais contemporâneos". Portanto, participar de um CA pode significar uma oportunidade de vivenciar experiências relacionadas com diferentes aspectos de aprendizado para a formação, aprimorando sua atuação nos âmbitos que está inserido, seja o profissional, social ou acadêmico. 


\subsection{O SECRETÁRIO EXECUTIVO E SUAS COMPETÊNCIAS}

Para que o profissional de Secretariado Executivo consiga se destacar no mercado são necessárias inúmeras qualificações. Para isso, as DCN do curso de graduação em Secretariado Executivo, em seu artigo $4^{\circ}$, asseguram a formação do perfil de um profissional que tenha:

[...]VI - domínio dos recursos de expressão e de comunicação compatíveis com o exercício profissional, inclusive nos processos de negociação e nas comunicações interpessoais ou inter-grupais; VII - receptividade e liderança para o trabalho em equipe, na busca da sinergia; [...] XII - eficaz utilização de técnicas secretariais, com renovadas tecnologias, imprimindo segurança, credibilidade e fidelidade no fluxo de informações; XIII - iniciativa, criatividade, determinação, vontade de aprender, abertura às mudanças, consciência das implicações e responsabilidades éticas do seu exercício profissional (BRASIL, 2005, p. 21).

Compreende-se, então, que as qualificações legitimadas pelas DCN abrangem diferentes aspectos da formação, tornando relevante qualquer atividade que possibilite a construção e o desenvolvimento de competências. Essas competências desenvolvidas, segundo Fleury e Fleury (2001) e Santos (2011), consistem em um conceito articulado entre três dimensões, conhecido como CHA (conhecimento, habilidades e atitudes), onde juntam-se o saber, o saber-fazer e o querer-saber-fazer.

Esse conhecimento é tido como uma série de informações que estão assimiladas e ordenadas de modo a conseguir dar ao indivíduo que as possui a capacidade de entender o mundo ao seu entorno (SANTOS, 2011). Já as habilidades, segundo Katz (1974), podem ser técnicas, aquelas ligadas à compreensão em um tipo específico de atividade, envolvendo procedimentos; humanas, aquelas relacionadas à aceitação de percepções, crenças e esforço cooperativo da equipe; e conceituais, aquelas que permitem a visualização da empresa como um todo, reconhecendo a importância das diversas funções de uma organização e a dependência entre elas. Por fim, as atitudes consistem em uma dimensão que está relacionada às iniciativas que são tomadas, uma vez que o indivíduo já tem o conhecimento e as habilidades (RUZZARIN; AMARAL; SIMINOVSCHI, 2002).

Souza (2004) ainda trata o estudo sobre o conceito de competência de modo a considerar a aplicação desse conjunto de elementos para atingir os objetivos propostos por uma organização. A autora classifica esse tipo de competência como competência gerencial e ainda a subdivide em três pilares: área pessoal, social e organizacional. Na área pessoal, os aspectos elencados são a comunicação interpessoal e autocontrole emocional. $\mathrm{Na}$ área social, a liderança

Revista Expectativa, Toledo/PR, v.20, n. 3, p. 22-45, jul./set., 2021. 
e negociação interpessoal se apresentam como os elementos que sustentam tal pilar. Por fim, a área organizacional é composta pelo planejamento estratégico, a programação e o controle de atividades. Sendo através do domínio de tais aptidões que os indivíduos conseguem atuar segundo uma conduta desejada pelas organizações.

Por sua vez, Kloss et al. (2018) apresentam os profissionais de secretariado como indivíduos que ao longo das últimas décadas tiveram que se adequar no que tange ao desenvolvimento das atividades. Sendo assim, estes passaram a ter um perfil profissional capacitado e de excelência, que busca junto à organização o cumprimento de metas. Assim, tendo novas competências que buscam qualificação, capacitação e proatividade no que diz respeito à função secretarial e a gestão dentro da organização.

Oliveira e Lohmann (2010) ainda apresentam o secretário executivo como um profissional que atua no ambiente organizacional com competências que podem estar ligadas diretamente aos recursos humanos. Tal desenvoltura nas empresas faz com que seu trabalho, que por vezes é desempenhado em equipe, possa motivar e melhorar desempenhos pessoais e coletivos, fazendo com que as constantes adaptações necessárias dentro das organizações sejam realizadas com mais facilidade.

Portanto, nota-se que o perfil do profissional de Secretariado pode e deve ser construído ao longo de sua trajetória, indo desde a formação oferecida pelas IES que pode ser implementada com experiências vivenciadas em CA, grupos de pesquisa, empresa júnior, estágio, dentre outros, contribuindo para uma maior amplitude no desenvolvimento de competências que correspondam à realidade fora do âmbito acadêmico. O perfil profissional deste ainda pode ser implementado ao longo de sua carreira no mercado devido o contato com experiências que conseguem moldá-lo e enriquecer seu rol de competências, gerando destaque no mercado de trabalho que avança continuamente nas exigências por constantes qualificações.

\section{PROCEDIMENTOS METODOLÓGICOS}

Esta pesquisa classifica-se, quanto à abordagem do problema, como qualitativa, pois considera a subjetividade de sujeitos pertencentes a um grupo, não se prendendo ao uso de métodos e técnicas estatísticas que visem numerar ou medir unidades. A abordagem qualitativa se ampara na qualidade e na essência das informações apuradas (PRODANOV; FREITAS,

Revista Expectativa, Toledo/PR, v.20, n. 3, p. 22-45, jul./set., 2021. 
2013). Neste estudo, a mesma se aplica, pois, a subjetividade do sujeito é aspecto presente quando se lida com uma pesquisa pautada no estudo de experiências vivenciadas, aqui no caso, as experiências vivenciadas na participação em um CA. Quanto aos objetivos, a pesquisa classifica-se como descritiva, pois busca descrever uma determinada realidade (VERGARA, 2014), apresentando como a experiência de um discente em um CA o afeta em diversos âmbitos.

Quanto aos procedimentos empregados, a pesquisa classifica-se, segundo Mascarenhas (2012), como um estudo de caso, visto que busca estudar uma organização específica para refletir sobre um conjunto de dados descrevendo um objeto de estudo. No presente estudo, tal procedimento ajuda a trazer informações acerca da maneira como se estabelece o desenvolvimento estudantil com a participação no Centro Acadêmico de Secretariado Executivo (CASEC).

A definição dos sujeitos participantes da pesquisa foi realizada mediante o atendimento de critérios determinados pelos autores, que consistiam em: 1) ser aluno ou exaluno do curso de Secretariado Executivo da UFC, 2) ter participado de alguma das seguintes gestões do CASEC: Gestão Inovadora (2016-2017), Gestão MAIS (2017-2018) e Gestão Motirõ (2018-2019); e 3) ter se disponibilizado voluntariamente para participar da pesquisa. Com isso, obteve a participação de 17 indivíduos no estudo.

Para a coleta de dados, realizou-se um convite aos sujeitos que correspondiam aos critérios definidos para a seleção da amostra. Após confirmação da participação na pesquisa, foi acordado, individualmente, o melhor momento para a realização da entrevista com os sujeitos. Devido à variedade de dias e horários combinados percebeu-se que a entrevista indireta seria o melhor instrumento para a coleta de dados, pois se baseia na não necessidade do encontro presencial do entrevistador com o entrevistado (KAUARK; MANHÃES; MEDEIROS, 2010). A entrevista, estruturada com uma questão introdutória sobre perfil dos entrevistados e seis questões subjetivas direcionadas aos objetivos da pesquisa, foi realizada entre os dias 12 e 16 de janeiro de 2019.

De posse de todos os áudios das entrevistas, realizou-se as transcrições. Em seguida, estas foram organizadas por questionamentos e os sujeitos da pesquisa foram nomeados com o termo "Entrevistado", seguido de um número natural, de modo que houvesse uma preservação da identidade dos indivíduos. Com isso, foi realizada a análise à luz das teorias utilizadas no referencial teórico, através da análise do conteúdo, uma vez que se buscou entender o 
pensamento dos indivíduos envolvidos com base nos conteúdos que estavam explícitos em forma de texto (CAREGNATO; MUTTI, 2006).

\section{APRESENTAÇÃO E ANÁLISE DOS RESULTADOS}

Esta seção apresenta os resultados e discussões dos dados obtidos através da realização de 17 entrevistas. Inicialmente, apresenta-se a entidade estudantil que foi utilizada no estudo de caso. Na subseção seguinte é exposto o perfil dos entrevistados, seguido pela apresentação de uma subseção referente aos motivos que levam o discente a participar do CA. Depois são apresentadas duas subseções que apresentam as competências ligadas às atividades do CASEC, sendo a primeira se abordando o CHA e a segunda abordando as competências gerenciais. E, por fim, três subseções que tratam a respeito do desenvolvimento acadêmico, profissional e social proporcionado pela atuação em um CA.

\subsection{APRESENTAÇÃO DA ENTIDADE ESTUDANTIL}

O Centro Acadêmico do Curso de Secretariado Executivo da UFC (CASEC) foi fundado em 03 de dezembro de 1997, com sede e foro na cidade de Fortaleza, configurando-se como uma entidade sem fins lucrativos. Sendo a entidade máxima representativa dos estudantes do curso de Secretariado Executivo da UFC com tempo de duração indeterminado, a mesma é constituída por uma diretoria que contém como cargos obrigatórios: presidente, vice-presidente, secretário geral, vice-secretário geral, diretor financeiro, diretor de relações estudantis, diretor de imprensa e marketing, diretor social e diretor de cultura e esporte (CENTRO ACADÊMICO DE SECRETARIADO EXECUTIVO, 1998).

Dentre as finalidades do CASEC, pode-se apontar a representação e a defesa dos direitos e reivindicações dos estudantes do curso; a promoção de encontros, palestras, conferências e debates de caráter social, político, cultural, científico, dentre outros, visando a complementação universitária; a participação em atividades que visem o bem do povo brasileiro, sendo solidário com as lutas da sociedade (CENTRO ACADÊMICO DE SECRETARIADO EXECUTIVO, 1998).

Revista Expectativa, Toledo/PR, v.20, n. 3, p. 22-45, jul./set., 2021. 


\subsection{PERFIL DOS ENTREVISTADOS}

Com o primeiro questionamento da entrevista procurou-se identificar o perfil dos entrevistados que formavam a amostra da presente pesquisa. Analisando os dados, foi possível perceber que dos 17 entrevistados, 14 são mulheres e 3 são homens. Quanto à idade dos entrevistados, percebeu-se que ela varia entre 19 e 23 anos.

Quando questionados se em algum momento houve atuação simultânea no CA e no mercado, por unanimidade, todos os 17 entrevistados responderam de maneira afirmativa. Destarte, percebe-se que há uma inserção muito cedo dos discente no mercado de trabalho e, assim, aspectos ligados ao desenvolvimento profissional podem ser notórios, uma vez que há essa conciliação, fato comentado no estudo de Cardoso e Sampaio (1994), que apresenta a sociedade como um agente que condiciona os indivíduos a manterem um contato direto entre o mercado de trabalho e as universidades.

Outra informação buscada foi em relação à quantidade de gestões que os discentes participaram. Foi observado que 11 sujeitos participaram apenas de uma única gestão do CASEC e 6 sujeitos participaram de duas gestões. Quando questionados quando ocorreu o ingresso no CASEC, dos 17 entrevistados, 1 sujeito ingressou no primeiro semestre do curso, 12 no terceiro, 1 no quarto e 3 no quinto. Com isso, percebe-se que grande maioria dos entrevistados ingressaram na entidade na fase inicial do curso de Secretariado Executivo, demonstrando um interesse precoce para participar do CA, o que nos leva a buscar a motivação para tal, assunto discutido na subseção seguinte.

\subsection{MOTIVAÇÕES RELACIONADAS AO INGRESSO NO CENTRO ACADÊMICO}

Os motivos relacionados ao ingresso no CA também foi um dos objetos de estudo dessa pesquisa. Quando perguntado aos entrevistados quais as razões que os levaram a participar do CA, inicialmente, percebeu-se um sentimento de pertencimento. Quanto a isso o Entrevistado 9 diz: "assim que eu entrei na UFC e escolhi o meu curso, eu visei fazer algo em prol dele [...]". Assim, percebe-se que a vontade de participar da entidade pode estar ligada ao que Marin et al. (2011) apontam em seu estudo, sobre a importância do CA no ensino e na formação dos discentes.

Revista Expectativa, Toledo/PR, v.20, n. 3, p. 22-45, jul./set., 2021. 
Outro motivo elencado foi a necessidade de mudança quanto a maneira como o CA atuava. O Entrevistado $7 \mathrm{diz:}$ “[...] a gente queria tornar o CA mais atuante [...], a gente queria trazer a presença do secretariado dentro da faculdade [...]”. O Entrevistado 2 complementa: “[...] eu queria trazer a presença do CA para os alunos.”. Assim, nota-se uma corroboração ao que Fonseca et al. (2018) alegam quanto a insatisfação com o funcionamento da entidade ser uma motivação para ingresso.

O movimento estudantil também foi apontado como razão de ingresso. Inicialmente o Entrevistado 1 fala sobre uma curiosidade em participar do mesmo: “[...] um dos motivos que fizeram eu escolher o CA de Secretariado foi a questão de saber como funcionava a representatividade estudantil no âmbito da academia.”. Já o Entrevistado 4 fala sobre permanência nele: "Eu sempre estava envolvida dentro da minha instituição, dentro da minha escola, com esses movimentos estudantis.". Tais colocações condizem com a importância do movimento estudantil apontada por Souza (1998) e com a forma como experiências passadas influenciam nas escolhas (FONSECA et al., 2018).

A vontade de viver as experiências oferecidas pela UFC também foi apontada. O Entrevistado 17 diz: “[...] eu queria participar o máximo possível de tudo que a universidade tem para me oferecer [...]". O Entrevistado 7 complementa esse pensamento sobre a universidade quando diz: “[...] eu queria aproveitar as oportunidades que ela me proporcionava e o CA foi o que diretamente me trouxe essa oportunidade, porque através do CA eu via que podia aprender [...]". Isso mostra que a motivação indicada por Oliveira (2017) é capaz de incentivar o discente a desenvolver algo, nesse contexto, estimula a participar do CA.

Razões ligadas ao aprimoramento profissional também foram apontadas. O Entrevistado 14 demonstra esse interesse quando diz que entrou no CA para "[...] ter novas experiências com gestão [...]”. Já o Entrevistado 5 via o CA como forma de “[...] adquirir experiência para usá-la no mercado de trabalho.”. Ambos os apontamentos corroboram com o pensamento de Silva et al. (2017), mostrando que essas motivações estão ligadas aos benefícios que o CA pode trazer para seus membros.

Assim, nota-se que mesmo existindo diferentes motivos para o ingresso na entidade, todos se mostram alinhados com os propósitos de um CA, trazendo o fortalecimento do movimento estudantil, o aproveitamento das oportunidades da universidade, a valorização do 
curso e o desenvolvimento profissional através de competências, assunto esse que será abordado na subseção seguinte.

\subsection{CONHECIMENTOS, HABILIDADES E ATITUDES NAS ATIVIDADES DO CENTRO ACADÊMICO}

Além das atividades específicas de cada diretoria do CA, existem momentos em que os membros precisam realizar funções que não são inerentes ao cargo que ocupam e que para a execução poderão exigir um certo domínio em conhecimentos, habilidades e atitudes. Assim, foi questionado quais conhecimentos, habilidades e atitudes estiveram relacionadas com as tarefas, atividades, ações ou projetos desenvolvidos no CA.

Para a realização das atividades típicas de um CA são necessários conhecimentos de gestão e das áreas de atuação da entidade. Uma das ações mais recorrentes no CASEC são os eventos que requerem conhecimento de cerimonial e protocolo. O Entrevistado 14 mostra como o CA precisa e ainda ajuda no desenvolvimento desse tipo de conhecimento quando diz: “[...] pude ter maior confiabilidade de como construir e conduzir eventos [...]”. Complementando, o Entrevistado $7 \mathrm{diz}$ que o aprimoramento sobre cerimonial foi capaz de auxiliá-lo no desenvolvimento de eventos acadêmicos e na sua atuação profissional, quando diz que o CA "[...] permitiu aplicar o que vi em sala de aula, podendo aprimorar o conhecimento teórico, trazendo ele numa perspectiva profissional".

Essas colocações corroboram com o entendimento de Santos (2011) em relação à vertente das competências que é pautada no conhecimento. O Entrevistado 1 ainda acrescenta que conteúdos secretariais, como: “[...] técnicas secretariais, assessoria executiva, organização de reunião [...]" são apenas alguns assuntos que compõem a rotina dos membros da entidade.

No que diz respeito às habilidades, o Entrevistado 15 explana como a habilidade técnica estava presente em suas atividades: “[...] eu tinha que ter habilidade com Facebook, eu criei um site, diria que habilidades mais tecnológicas. Criei várias artes temáticas, criei a logo do CA.”. Complementando, o Entrevistado 4 diz: “[...] meu cargo era de Secretária Geral e nesse caso, as funções que exigiam da gente era muito a questão da elaboração de documentos oficiais, como ofícios, memorandos e atas das reuniões.”. Dessa forma, nota-se que 
convergência em relação ao pensamento de Katz (1974), onde o autor afirmava que as habilidades técnicas demandam conhecimentos especializados.

Também foi possível identificar habilidades humanas, onde Katz (1974) aponta que as relações estabelecidas entre os indivíduos necessitam de aceitação de pontos de vista diferentes. Acerca disso, o Entrevistado 3 diz: "[...] nós precisamos mais do que trabalhar em grupo, nós precisamos, mesmo diante das discordâncias, ouvir, talvez não concordar, mas ver que nem sempre sua opinião é a melhor [...]". Assim, nota-se a importância do respeito entre os discentes em prol dos objetivos da entidade. Katz (1974) ainda fala da necessidade de cooperação, como pontuado pelo Entrevistado 13: "[...] poder sugerir melhorias ou colaborar de alguma forma em momentos que poderia ter atividades que fugiam da minha diretoria [...]”.

Ainda em relação às habilidades, o Entrevistado 7 trata a questão da entidade estudantil em sua totalidade: “[...] fazíamos também uma atividade de motivação dos nossos membros, para manter eles juntos e com a mesma motivação que eles tiveram para entrar. A gente queria que eles realizassem bem as atividades.", corroborando com a explanação acerca da habilidade conceitual discorrida por Katz (1974), relacionando que a organização depende do trabalho de todas as funções existentes.

Em relação às atitudes que compõem o conceito de competência (FLEURY; FLEURY, 2001), foi possível perceber que a proatividade é uma das atitudes exigidas no CA. Quanto a isso, o Entrevistado 11 diz: “[...] você tem que ser proativa [...], estar ali para resolver os problemas e fazer as coisas acontecerem independente do que vier [...]" e ainda diz que diante da rotina do CA, há situações difíceis em que "[...] tem que ter o pulso firme, você tem que ser proativa, você tem que tomar as rédeas e fazer o negócio andar.” (ENTREVISTADO 11). Com isso, nota-se uma convergência com Silva et al. (2017), onde os autores ressaltam que a proatividade pode ser entendida não apenas como um requisito do CA, mas como um dos benefícios gerados pela participação. O Entrevistado 17 ainda complementa: “[...] nós temos que ter uma proatividade, uma pontualidade, todos nós temos que ter compromisso, ter muita organização, muita responsabilidade no que a gente está fazendo.”. Assim, percebe-se um engajamento dos membros, corroborando com Ruzzarin, Amaral e Siminovschi (2002) em relação às atitudes como um artifício de alcance de eficácia nos processos organizacionais.

Dessa forma, nota-se que a participação dos discentes no CA não apenas necessita, como também pode oportunizar o desenvolvimento de conhecimentos secretariais, como 
eventos, cerimonial, protocolo, assessoria executiva e reuniões; habilidades técnicas, humanas e conceituais, pertinentes para qualquer organização; e, ainda, atitudes que são valorizadas no mercado, como proatividade, pontualidade, compromisso e responsabilidade. Considerando a junção dos três assuntos tratados nesta subseção, tem-se o CHA, o primeiro conceito de competência estudado nesta pesquisa. Assunto que continuará sendo abordado na subseção seguinte, porém com um olhar voltado para as competências gerenciais.

\subsection{COMPETÊNCIAS GERENCIAIS NAS ATIVIDADES DO CENTRO ACADÊMICO}

A vivência em um CA pode apresentar possibilidades para o desenvolvimento de competências gerenciais dos discentes devido à prática de ações, projetos e atividades que buscam atingir os objetivos traçados nessa entidade estudantil. Assim, foi questionado aos participantes quais as competências que estiveram relacionadas com as experiências vivenciadas no CA.

O Entrevistado 12 afirma que a comunicação foi uma das competências trabalhadas durante sua participação "[...] comunicar tanto interna, como externamente, tanto dentro do CA, quanto com a coordenação, com diretoria da faculdade, assim também com os discentes, não só do nosso curso.”. Os demais entrevistados que também pontuaram essa competência reafirmam a importância do desenvolvimento da comunicação interpessoal para êxito em suas atividades, como o Entrevistado 7 “"...] a gente tinha que entrar em contato com os palestrantes que iam para os eventos, eram pessoas que precisam de uma linguagem mais formal e de um comportamento diferente também.”.

Essas colocações corroboram com o entendimento de Souza (2004) acerca da competência na área pessoal, que apresenta a comunicação interpessoal como uma das unidades pertencentes a esse âmbito. Além desse, a autora cita também o autocontrole emocional, também apontado pelos participantes da pesquisa, como na fala do Entrevistado 7 “[...] a parte que mais me chamava atenção e o que a gente mais fazia, era planejamento de ações e atividades, mas havia muito imprevisto e a gente tinha que saber lidar.”. Assim, diante dos imprevistos, das dificuldades, havia a preocupação em executar as ações de maneira eficaz, exigindo então controle emocional dos discentes para conseguir conduzir essas situações.

Revista Expectativa, Toledo/PR, v.20, n. 3, p. 22-45, jul./set., 2021. 
Além desses elementos nas competências voltadas para a área pessoal, Souza (2004) elenca a liderança como uma competência pertencente a uma unidade de desempenho social, destacado também pelos participantes como presente nas experiências no CA, como apresentado pelo Entrevistado 6: "[...] a gente tem que saber liderar pessoas, saber fazer com que elas consigam desempenhar bem aquelas funções e encaminhá-las até isso.”, no mesmo raciocínio o Entrevistado 16 diz: “[...] quando a gente é líder, a gente tem uma grande missão, que é de ser uma inspiração para os outros, é ser uma pessoa que seja uma espécie de exemplo, tanto dentro, quanto fora da universidade, [...]". Percebe-se, através das considerações dos entrevistados, que diante dos projetos, ações ou atividades, eles tiveram oportunidade de colocar em prática ou desenvolver a liderança no CA.

Correspondendo aos elementos destacados por Souza (2004) quanto às competências da área organizacional, os entrevistados também apontaram o planejamento e a programação de projetos como relevantes, sendo essas considerações perceptíveis no relato do Entrevistado 7, onde o cargo que exercia exigia, em parceria com o presidente da gestão, “[...] planejamento, acompanhamento das atividades, organização de eventos, distribuição de tarefas, [...]", assim como respondido pelo Entrevistado 14, onde a diretoria de projeto "[...] fica responsável pelo planejamento, toda a parte da estrutura, coffee break, iluminação, som, essas coisas.”.

Dessa forma, percebe-se que a comunicação, o controle emocional, a liderança, o planejamento e a programação de projetos podem ser desenvolvidos em aspecto geral, considerando a totalidade da entidade; e específico, nas diretorias, de acordo com os projetos, ações e atividades trabalhadas. Assim, infere-se que as competências elencadas pelos entrevistados abrangem esferas de nível pessoal, interpessoal e de entidade. Com isso, nota-se que o contato com essas competências pode auxiliar no desenvolvimento do discente em vários aspectos, assunto tratado na subseção seguinte, que trabalha o desenvolvimento acadêmico dos membros do CA.

\subsection{CENTRO ACADÊMICO E O DESENVOLVIMENTO ACADÊMICO}

A formação do indivíduo vai muito além daquela adquirida com o conteúdo didático em sala de aula. O contato com as diversas oportunidades que as IES oferecem, afeta o desenvolvimento acadêmico do aluno. Dessa forma, foi indagado aos entrevistados quais os

Revista Expectativa, Toledo/PR, v.20, n. 3, p. 22-45, jul./set., 2021. 
benefícios que a participação no CA trazia para o desenvolvimento acadêmico daqueles que o integram.

Inicialmente, foram levantados pontos relacionados a responsabilidade acadêmica e a junção de teoria e prática. Quanto ao primeiro ponto, o Entrevistado 3 afirma: “[...] eu vejo que o CA me traz muito senso de responsabilidade.”. Já quanto ao segundo ponto, é levantado como essa conciliação ajuda no melhor aproveitamento dos conteúdos, isso pode ser comprovado pelo Entrevistado 7 quando diz: "Eu pude trazer a teoria para prática. Eu pude aplicar o que aprendi em sala de aula dentro do CA. Eu conseguia aprimorar esses conhecimentos [...]”. Assim, nota-se que há uma corroboração com o pensamento de Marin et al. (2011) quanto a questões voltadas para o desenvolvimento do ensino e formação do discente.

Ainda na vertente do desenvolvimento estudantil frente ao que é posto por Marin et al. (2011) quanto ao ensino, outro ponto levantado pelos entrevistados foi a aproximação entre corpo docente, corpo discente, coordenação, diretoria e CAs. Como fruto dessa aproximação, o Entrevistado 6 diz: “[...] a gente passa a estar mais informado do que acontece na faculdade, seja um evento, um curso, e isso é bem importante também.”. Já o Entrevistado 16 fala que através dessa aproximação é formada uma rede de contatos: “[...] a network que traz é muito bacana e isso, querendo ou não, dá um incentivo maior para gente estar procurando mais conhecimentos da nossa área [...]”.

O CA ainda pode auxiliar no desenvolvimento acadêmico com a possibilidade de uma maior participação no ambiente universitário. Acerca disso o Entrevistado 5 diz: “[...] estou mais engajada na universidade e os conhecimentos adquiridos com a experiência estão ajudando demais.". Já o Entrevistado 4 diz: "Como CA, acredito que nos tornamos alunos mais ativos [...]. Como CA a gente acaba contribuindo de alguma forma para a nossa academia.”. Essa contribuição também é apontada pelo Entrevistado 7 quando diz: “A gente trabalha também com o intuito de trazer contribuição para o nosso curso [...]". Dessa forma, percebe que a participação do membro do CA no ambiente acadêmico não se restringe a um elo entre coordenação, docentes e discentes (SILVA et al., 2017) ela ultrapassa esse aspecto, tornando o discente um agente de mudança, podendo contribuir para o crescimento do curso e para a formação de todos os discentes.

Portanto, infere-se que a participação no CA pode possibilitar que o desenvolvimento acadêmico seja afetado e aprimorado de diferentes formas. A entidade pode impulsionar seus 
membros a usufruir mais da universidade, aproveitando as oportunidades que são oferecidas e instigando novas formas de busca por aprendizado, valorizando a network possibilitada e a contribuição que a participação acadêmica pode trazer. Além disso, esse melhor aproveitamento das oportunidades acadêmicas pode auxiliar na área profissional, assunto tratado na próxima subseção.

\subsection{CENTRO ACADÊMICO E O DESENVOLVIMENTO PROFISSIONAL}

Experiências que contribuem para o aprimoramento profissional são bastante valorizadas no ambiente mercadológico. Por isso, foi perguntado aos entrevistados quais os benefícios que a participação no CA trazia diretamente para o desenvolvimento profissional daqueles que fazem parte da entidade.

Inicialmente, notou-se esse impacto quando o Entrevistado 5 aponta o benefício que a atuação traz: “[...] o CA só está somando na minha profissional.”. Já o Entrevistado 4 diz: “[...] nós já vamos nos preparando de uma forma diferente e quando isso nos é cobrado na vida profissional, a gente já tem um olhar diferenciado.”. Assim, percebe-se a importância da entidade no quesito preparo para o mercado de trabalho.

Contrapondo o fato de que um CA não é uma empresa (LAUERMANN et al., 2012), os membros o encaram como tal. A respeito disso, o Entrevistado 7 diz: “[...] o CA é como se fosse uma empresa voltada para os alunos, que teus clientes são os teus alunos e que a tua equipe são os teus colegas de sala de aula, então isso te dá oportunidade de pensar como profissional, [...]”, complementando, o Entrevistado 17 diz: “[...] eu sempre tratei o CA como empresa, então fez com que eu tratasse ele de uma forma mais rigorosa, com questões de pontualidade, com as atividades, com os prazos.". Dessa forma, percebe-se que, quando a entidade é tratada com a mesma seriedade de uma empresa, a mesma pode proporcionar aos seus membros experiências valorosas.

As experiências apontadas pelos entrevistados estão ligadas a maneira como as competências (FLEURY; FLEURY, 2001; SOUZA, 2004) que são desenvolvidas no CA agregam valor em sua formação profissional. Questões voltadas aos conhecimentos gerados; às habilidades técnicas, humanas e conceituais desenvolvidas; às atitudes aprimoradas, além das competências pessoais, sociais e organizacionais que podem ser potencializadas. Confirma-se

Revista Expectativa, Toledo/PR, v.20, n. 3, p. 22-45, jul./set., 2021. 
isso quando o Entrevistado 15 diz: “[...] essas habilidades e competências desenvolvidas dentro do CA também ajudam muito no mercado.”. Com isso, nota-se o impacto e o aprimoramento profissional apontados por Silva et al. (2017).

Além dessas competências, outro ponto foi mencionado pelos entrevistados, foi o trabalho em equipe. Em relação a isso, o Entrevistado 3 diz: "[...] eu vejo que o trabalho em grupo, a compreensão, a escuta do CA, são fatores que me ajudam muito no meu ambiente profissional.”, complementando, o Entrevistado 16 diz: “[...] a gente aprende também a lidar com as pessoas, cada pessoa tem seu limite, cada pessoa pode fazer isso, as pessoas têm competências diferentes, têm habilidades diferentes, então assim, saber diferenciar melhor o grupo que você tem.”. Posto isso, percebe-se que o CA, sendo uma organização articulada por pessoas (MEIRELES, 2003), afeta a vida dos seus membros, possibilitando uma melhor atuação nas suas equipes de trabalho, como apontado no estudo de apontado por Oliveira e Lohmann (2010).

Deste modo, nota-se que a participação em uma gestão de CA pode afetar o desenvolvimento profissional daqueles que o integram. Assim, tratar a entidade com seriedade, pode proporcionar contato com competências que normalmente são exigidas no mercado de trabalho. Esse contato não se prende às questões voltadas à área profissional, o contato com causas sociais também é possibilitado pelo CASEC, impactando o âmbito social, assunto abordado na subseção seguinte.

\subsection{CENTRO ACADÊMICO E O DESENVOLVIMENTO SOCIAL}

Ter em si um sentimento em prol do desenvolvimento da sociedade por meio de ações e projetos garante benefícios para todos os envolvidos. As IES, como formadora de cidadãos, e o CA, como um auxiliar, podem e devem fazer parte desse desenvolvimento. Com isso, foi questionado aos entrevistados quais os benefícios da participação no CA para a formação social dos seus membros.

Inicialmente, notou-se que a importância de impactos na vertente social dos membros da entidade quando o Entrevistado 5 diz: "Ao ser membro do CA, passamos a ter uma visão diferente da universidade e logo da sociedade também.”, complementando o Entrevistado 10 diz: “[...] a melhor parte do CA é isso, é saber que o seu trabalho não está apenas ajudando, 
auxiliando alunos, mas também a comunidade.”. A importância de ações desse tipo é vista quando o Entrevistado 17 diz: "Participar de algo que vá beneficiar outros [...] faz com que eu me sinta útil para a sociedade.”. Dessa forma, percebe-se que a participação em um CA proporciona um crescimento social, dando aos seus membros uma maior ciência da necessidade de se importar com questões que ultrapassam os muros da universidade.

Essas colocações corroboram com o pensamento de Silva et al. (2017) acerca da filantropia que está envolvida na atuação dos CAs, principalmente em seus projetos e ações. Dado isso, na pesquisa foi possível identificar ações e projetos realizados que puderam contribuir para a formação social dos membros da entidade, como as campanhas para doação de sangue. A importância dessa ação é vista quando o Entrevistado 7 diz: "Através da doação de sangue, eu tive a oportunidade de ultrapassar esses muros da universidade, não somente no sentido literal da palavra, os muros físicos, porque a doação de sangue foi para todo mundo, aberta ao público [...]". O Entrevistado 16 ainda alega que a ação "[...] não nos custou nada e mesmo ela não custando nada, conseguiu ajudar várias pessoas [...]”.

Ainda na vertente filantrópica de Silva et al. (2017), o CASEC também realiza ações voltadas para a causa animal, confirma-se isso com a fala do Entrevistado 13: "O CA também realiza extensão, posso citar atividades solidárias que realizamos para o Lar Tintin, abrigo de animais [...]". A afeição por esse projeto é explicitada pelo Entrevistado 17 quando diz: “Fizemos uma ação, o 'Halloween do Lar Tintin', onde a gente divulgou esse projeto para os estudantes da faculdade e foi muito gratificante porque a gente pode ajudar uma pequena parcela da sociedade com grupo ali de nove/dez participantes[...]”.

Outro projeto mencionado foi o "Caminhos do Saber", que ofertava cursos gratuitos para a sociedade, fruto da Associação de Estudos e Pesquisa Tecno-Científica (APEC), o projeto contava com a participação de membros do CA como professores voluntários. O Entrevistado 17 aponta a participação no projeto como uma chance de propagação e divulgação do curso: "O projeto 'Caminhos do Saber', [...] fazia com que a gente, não apenas CA, mas outros estudantes, passasse seu conhecimento do curso [...]". O Entrevistado 6 demonstra apreço quando diz: "[...] foi bem bacana porque a gente realmente dava aula no curso de Secretariado [...]". O "Caminhos do Saber" comprova em partes o que é dito por Marin et al. (2011) quanto o papel do CA no desenvolvimento do ensino, porém mostra que o CASEC não se prende ao desenvolvimento do ensino ofertado na IES de origem, agregando assim 
conhecimento à sociedade, tornando aqueles que participam da entidade agentes de impacto social.

Dessa forma, nota-se que ações e projetos voltados para a sociedade, seja para causas voltadas à saúde, seja para a causa animal, ou até mesmo para a disseminação de conhecimento, podem garantir impacto nos participantes do CA, proporcionando um melhor desenvolvimento social e trazendo para a sociedade cidadãos que possuem um maior engajamento com as causas nobres.

\section{CONSIDERAÇÕES FINAIS}

O desenvolvimento desse estudo possibilitou algumas percepções acerca da influência da participação do discente de Secretariado Executivo em uma entidade estudantil como o CA, explicitando como a atuação na entidade pode influenciar em sua formação nas vertentes acadêmica, profissional e social, enriquecendo estudos acerca dessa temática.

Os objetivos traçados para essa pesquisa foram alcançados. Quanto ao primeiro objetivo específico, ligado aos motivos relacionados à escolha do discente em participar do CASEC, foi possível identificar na pesquisa diversas razões que levam o aluno a querer ser membro da entidade estudantil, como o fortalecimento do movimento estudantil, o aproveitamento das oportunidades da universidade, a valorização do curso e o desenvolvimento profissional. Além disso, pode-se salientar que todas essas motivações estão ligadas aos propósitos desse tipo de entidade.

A respeito das competências que estão relacionadas com as atividades desenvolvidas pelos discentes no CA, segundo objetivo específico do estudo, identificou-se na atuação dos estudantes o contato e o desenvolvimento de conhecimentos voltados para área de secretarial; habilidades técnicas, humanas e conceituais; e atitudes como proatividade, pontualidade, compromisso e responsabilidade. Estas três vertentes integram o conceito de competência pautado no CHA. Além disso, foi possível apontar o desenvolvimento de competências gerenciais pautadas na vertente pessoal, social e organizacional. Dessa forma, percebe-se que o desenvolvimento dessas competências se torna um diferencial para a formação dos discentes de Secretariado Executivo, visto que poderão ter mais possibilidades para corresponder às exigências do mercado e da sociedade.

Revista Expectativa, Toledo/PR, v.20, n. 3, p. 22-45, jul./set., 2021. 
Em relação aos benefícios da participação em um CA para a formação acadêmica, profissional e social do discente, terceiro objetivo específico, notou-se que a vertente acadêmica é desenvolvida e aprimorada, uma vez que o discente passa a usufruir mais da universidade, aproveitando as oportunidades que são oferecidas, e busca novas formas de aprendizado. A vertente profissional é beneficiada, pois a entidade estudantil garante o contato com competências que normalmente são exigidas no ambiente mercadológico. E, por fim, na vertente social, o CA consegue colaborar para a formação de cidadãos mais engajados com causas nobres da sociedade devido o contato com ações e projetos sociais.

Com os resultados da pesquisa foi possível conhecer como a participação do discente no CA interfere diretamente no desenvolvimento acadêmico, profissional e social, mostrando que a entidade pode agregar valor por garantir o contato com competências e com o movimento estudantil; oportunizar a conciliação da teoria com a prática; aumentar o engajamento e a participação na universidade e no próprio curso; e propiciar o contato com causas sociais nobres, contribuindo para a cidadania.

No caso estudado, pode-se observar que a instituição pública UFC consegue proporcionar ao aluno de Secretariado Executivo uma formação mais abrangente, não se limitando ao aprendizado em sala de aula. Percebeu-se, também, que o CA, sendo uma entidade estudantil, uma vez que consegue atuar com seriedade no âmbito universitário, torna-se capaz de contribuir para a formação acadêmica, trazendo aos discentes de Secretariado melhores resultados e ao curso um maior fortalecimento; profissional, dando ao estudante um maior preparo paras as rotinas secretariais e gerenciais; e social, oportunizando um engajamento na sociedade, garantindo um retorno àqueles que investem na educação.

Quanto às limitações que se apresentaram durante a realização desse estudo, destacase a escassez de referencial teórico que aborde temáticas relacionadas às entidades estudantis que pudessem servir de embasamento. Já em relação às sugestões de novas pesquisas, sugerese estudar os desafios acadêmicos, pessoais e sociais da participação do discente em um CA, tendo em vista que é uma atividade extracurricular, demandando tempo e dedicação extra. Também se sugere a reaplicação do estudo em outros CAs, buscando descobrir possíveis paridades e divergências com o presente estudo. E, por fim, propõe-se pesquisar como um CA consegue desenvolver competências voltadas para gestão de pessoas, de projetos, de eventos e para planejamento estratégico.

Revista Expectativa, Toledo/PR, v.20, n. 3, p. 22-45, jul./set., 2021. 


\section{REFERÊNCIAS}

BRASIL. Lei n ${ }^{\circ} 7.395$, de 31 de outubro de 1985. Dispõe sobre os órgãos de representação dos estudantes de nível superior e dá outras providências. Diário Oficial [da] República Federativa do Brasil, Poder Executivo, Brasília, DF, 31 out. 1985.

BRASIL. Lei no 9.394, de 20 de dezembro de 1996. Estabelece as diretrizes e bases da educação nacional. Diário Oficial [da] República Federativa do Brasil, Poder Executivo, Brasília, DF, 20 dez. 1996.

BRASIL. Resolução n ${ }^{\circ}$ 3, de 23 de junho de 2005. Institui as Diretrizes Curriculares Nacionais para o curso de graduação em Secretariado Executivo e dá outras providências. Diário Oficial [da] República Federativa do Brasil, Poder Executivo, Brasília, DF, 23 jun. 2005.

CARDOSO, R. C. L; SAMPAIO, H. Estudantes universitários e o trabalho. Revista Brasileira de Ciências Sociais, São Paulo, v. 9, n. 26, p. 30-49, out. 1994.

CAREGNATO, R. C. A.; MUTTI, R. Pesquisa qualitativa: análise de discurso versus análise de conteúdo. Texto \& Contexto Enfermagem, Florianópolis, v. 15, n. 4, p. 679-684, dez. 2006.

CAVALCANTE, D. N. S. et al. Semana do bixo do CAET: um caso de sucesso no combate à evasão de calouros no curso de Engenharia de Telecomunicações do IFCE. In: Congresso Brasileiro de Educação em Engenharia, 42, 2014, Juiz de Fora. Anais [...]. Juiz de Fora: ABENGE, 2014, p. 1-12. Disponível em: https://cutt.ly/LyQ3ySl. Acesso em: 21 dez. 2018.

CENTRO ACADÊMICO DE SECRETARIADO EXECUTIVO - CASEC/UFC. Estatuto do CASEC/UFC. Fortaleza, 1998.

COSTA, M. F. O. et al. O Papel do Centro Acadêmico na Formação Cidadã do Universitário: um estudo de caso dos usuários do CABIRG/UFC. Revista Folha de Rosto, Juazeiro do Norte, v. 3, n. 1, p. 5-15, jan./jun. 2017.

FLEURY, M. T. L.; FLEURY, A. Construindo o conceito de competência. Revista de Administração Contemporânea, Curitiba, v. 5, n. spe, p. 183-196, 2001.

FONSECA, J. C. F. et al. Gestão de um diretório acadêmico: um olhar sobre as organizações do movimento estudantil a partir da psicologia do trabalho e das organizações. Pretextos -

Revista da Graduação em Psicologia da PUC Minas, Belo Horizonte, v. 3, n. 5, p. 411430, jan./jun. 2018.

KATZ, R. L. Skills of an effective administrator. Harvard Business Review, Watertown, v. 52, n. 5, p. 90-102, sept. 1974. 
KAUARK, F. S.; MANHÃES, F. C.; MEDEIROS, C. H. Metodologia da pesquisa: Um guia prático. Bahia: Via Litterarum, 2010.

KILIMNIK, Z. M.; SANT’ANNA, A. S.; LUZ, T. R. Competências profissionais e Modernidade organizacional: coerência ou contradição? RAE - Revista de Administração de Empresas, São Paulo, v. 44, n. spe, p. 10-21. 2004.

KLOSS, C. T. et al. As competências secretariais como ferramenta de consultoria. Revista Expectativa, Toledo, v. 17, n. 2, p. 1-23, jul./dez. 2018.

LAUERMANN, J. D. et al. Planejamento estratégico: importante instrumento de gestão para um diretório acadêmico. In: Simpósio de Ensino, Pesquisa e Extensão/SEPE - Aprender e empreender na educação e na ciência, 16, 2012, Santa Maria. Anais [...]. Santa Maria: UFN, 2012, p. 1-6. Disponível em: https://cutt.ly/9yQ9h2h. Acesso em: 21 dez. 2018.

MARIN, V. et al. A influência das atividades realizadas por um centro acadêmico em uma formação completa em engenharia. In: Congresso Brasileiro de Educação em Engenharia, 39, 2011, Blumenau. Anais [...]. Blumenau: ABENGE, 2011, p. 1-10. Disponível em: https://cutt.ly/ayQ3ruD. Acesso em: 21 dez. 2018.

MASCARENHAS, S. Metodologia científica. 1. ed. São Paulo: Pearson Education do Brasil, 2012.

MEIRELES, M. Teorias da administração: clássicas e modernas. São Paulo: Futura, 2003.

MÜLLER, R.; OLIVEIRA, V. S.; CEGAN, E. Perfil do (a) profissional de Secretariado Executivo na gestão contemporânea: evidências a partir dos ingressantes no mercado de trabalho na cidade de Curitiba, e das demandas empresariais. Revista de Gestão e Secretariado, São Paulo, v. 6, n. 3, p. 129-151, set./dez. 2015.

OLIVEIRA, A. J. G. R.; LOHMANN, M. R. O profissional de Secretariado Executivo no suporte à gestão escolar. Revista Intersaberes, Curitiba, v. 5, n. 9, p. 132-143, jan./jun. 2010.

OLIVEIRA, E. S. Motivação no ensino superior: estratégias e desafios. Contexto \& Educação, Ijuí, v. 32, n. 101, p. 212-232, jan./abr. 2017.

PRODANOV, C. C.; FREITAS, E. C. D. Metodologia do Trabalho Científico: Métodos e Técnicas da Pesquisa e do Trabalho Acadêmico. 2. ed. Novo Hamburgo: Feevale, 2013.

RUZZARIN, R.; AMARAL, A.; SIMINOVSCHI, M. Gestão por competências: indo além da teoria. Porto Alegre: Sebrae/RS, 2002.

SANTOS, A. P. Conhecimentos, habilidades e atitudes: o conceito de competências no trabalho e seu uso no setor público. Revista do Serviço Público, Brasília, v. 62, n. 4, p. 369386, out./dez. 2011. 
SILVA, G. J. V. et al. Contribuições do Centro Acadêmico de Química para a formação profissional dos graduandos: em foco o empreendedorismo e a extensão universitária. Revista ELO - Diálogos em Extensão, Viçosa, v. 4, n. 2, p. 14-24, out. 2017.

SOUZA, F. C. Movimento estudantil em biblioteconomia: um olhar sobre a UFSC ou A importância do movimento estudantil para a formação profissional. Encontros Bibli: revista eletrônica de biblioteconomia e ciência da informação, Florianópolis, v. 3, n. 6, p. 48-62, jan. 1998.

SOUZA, R. L. S. Gestão por competências no governo federal brasileiro: experiência recente e perspectivas. In: Congreso Internacional del CLAD sobre la Reforma del Estado y de la Administración Pública, 9, 2004, Madrid. Anais [...]. Madrid: CLAD, 2004, p. 1-20. Disponível em: https://cutt.ly/SyQ3nOn. Acesso em: 27 jan. 2019.

VERGARA, S. C. Projetos e relatórios de pesquisa em administração. 15. ed. São Paulo: Atlas, 2014. 